IV Congreso Internacional Estética y Política Poéticas del desacuerdo para una democracia plural 16 y 17 de octubre. Valencia

Doi: http://dx.doi.org/10.4995/CEP4.2019.10504

\title{
La función política del arte a través de la industria cultural
}

\section{Camilo Segura Moreno}

Valencia.

\begin{abstract}
Culture industry term directly links to aesthetic and political elements. Through this concept, we aim to analyze three political consequences it has in society: leisure as job complement, the impact of advertisement in society, and the capability of this industry to exclude everyone that tries to escape from it. Once analyzed these characteristics, we will analyze the state of the art in our societies, while proposing the role it could take to contribute on searching alternatives to the hegemonic capitalist system.
\end{abstract}

Keywords: culture industry, art, politics, leisure, advertisement.

\section{Resumen}

El término industria cultural nos remite directamente tanto a elementos estéticos como políticos. A través de este concepto, pretendemos analizar tres consecuencias políticas que tiene en la sociedad: el ocio como extensión del trabajo, el papel de la publicidad en nuestras sociedades y la capacidad de esta industria para excluir a todo aquel que intenta salir de ella. Vistas estas características, analizaremos el estado del arte en nuestras sociedades, así como plantear cuál podría ser la función de este contribuyendo a buscar alternativas al sistema capitalista hegemónico.

Palabras clave: industria cutural, arte, política, ocio, publicidad. 


\section{Introducción}

El término industria cultural nos remite directamente tanto a elementos estéticos como políticos. Los cambios materiales que tuvieron lugar en el siglo XIX y XX produjeron un cambio cualitativo en la forma de producir y recibir arte. Frente a algunas posiciones más favorables a estos cambios, como la de Walter Benjamin, Adorno y Horkheimer criticaron los efectos políticos y sociales que esta industria cultural tienen para las sociedades. Como leemos en Dialéctica de la Ilustración (Adorno y Horkheimer, 2007) estos nuevos métodos forman parte del mismo sistema capitalista que rechaza aprovechar la técnica para cuestiones sociales como acabar con el hambre.

Este concepto aparece por primera vez en los años 40 del pasado siglo, cuando Adorno traslada sus análisis de la música al complejo entramado político y social que supone la industria cultural. Durante este periodo, la Escuela de Frankfurt percibe cada vez más alejada la revolución proletaria, creyendo que el sujeto revolucionario del que hablaba Marx había renunciado al papel que este le había asignado en la historia. Esta aproximación a la idea de industria cultural supondrá una consecuencia de la búsqueda de respuesta a la pregunta que plantea Adorno en Minima Moralia: «Los sociólogos se ven enfrentados a una desconcertante adivinanza: ¿dónde está el proletariado?» (Adorno, 2006, p. 202).

Pero, ¿cuáles son las consecuencias que tiene la industria cultural para la sociedad? ¿Cuál es la relación entre arte, política y los individuos? ¿De qué manera condiciona nuestra forma de entender el mundo y todo lo que nos rodea?

En la introducción queremos destacar cómo esta industria cultural colabora en el desarrollo de un sistema hegemónico en el que, como observó Adorno al llegar a América, «se habían desarrollado formas más suaves de obligado conformismo» (Jay, 1988, p. 282), quizás en un ámbito más eficaz: en el campo cultural. La industria cultural sirve para esclavizar a las personas de una forma más eficaz y sutil que los métodos anteriores. En esta línea consideramos que se puede entender también la teoría gramsciana sobre Europa occidental y las «sobreestructuras políticas creadas por el desarrollo superior del capitalismo» (Gramsci, 2013), las cuales dificultaban la revolución, todo lo cual le llevaría a formular el concepto de hegemonía.

Por eso el análisis de Tocqueville se ha confirmado, como recoge Adorno en La Industria Cultural: Ilustración como engaño de masas cuando expresa que ahora la tiranía deja el cuerpo para ir al alma; el amo ya no amenaza con pensad como yo o moriréis, sino que ahora se expresa en los términos de «sois libres de no pensar como yo. Vuestra vida, vuestros bienes, todo lo conservaréis, pero a partir de ese día seréis un extraño entre nosotros» (Adorno y Horkheimer, 2007, p. 146).

A continuación, veremos tres consecuencias directas de la industria cultural en la sociedad: el ocio como extensión del trabajo, el papel de la publicidad en nuestras sociedades y cómo la industria cultural es capaz de excluir a aquel que se sale de la mecánica impuesta. Una vez vistas estas tres consecuencias, esbozaremos algunas líneas de lo que consideramos podría ser una huida del sistema totalizador que supone la industria cultural.

\section{El ocio como extensión del trabajo}

La primera consecuencia política que queremos analizar es el ocio como una extensión velada del trabajo. Ello implica que la alienación del ser humano en las sociedades modernas va más allá del ámbito del trabajo, ampliándose a todas las esferas de la vida.

En este sentido es en el que se expresa Horkheimer en su correspondencia con Löwenthal, cuando defiende que «los mecanismos que gobiernan al hombre en su tiempo de ocio son absolutamente los mismos que lo gobiernan cuando trabaja. Llegaría hasta el extremo de decir que todavía hoy la clave para la comprensión de los modelos de conducta en la esfera de consumo es la situación del hombre (...) en el lugar de trabajo.» (Jay, 1988, p. 350)

El rechazo por parte de Adorno y Horkheimer a los productos de tal industria cultural debe entenderse en esta comprensión de tal aspecto de la cultura no como regocijo o camino hacia la felicidad, sino como la continuación de los esquemas impuestos en el trabajo por otros medios. 
En Minima Moralia, Adorno expone claramente lo que aquí queremos decir. En Vándalos nos muestra cómo el "tiempo libre" no es realmente tal. Siempre tenemos algo que hacer, debemos aprovecharlo de cualquier forma, planificando qué hacer en todo momento. Las formas del proceso de producción «se repiten en la vida privada o en los ámbitos del trabajo ajenos a dichas formas» (Adorno, 2006, p. 144). Los individuos, en las horas destinadas aparentemente a ejercer la libertad que el trabajo no les permite, actúan siguiendo las directrices de la industria cultural. Estas personas, que conforman la agrupación o la masa amorfa, dice Adorno que «a quienes más se parecen son a los drogadictos» (Adorno, 2006, p. 145). La religión ha dejado de ser el opio del pueblo o, al menos, ha disminuido su ímpetu; ahora lo es la industria cultural.

El tiempo libre sería de esta forma, un reflejo certero del ritmo de la producción. El tiempo libre o la diversión aparecen aquí como «la prolongación del trabajo bajo el capitalismo tardío. Es buscada por quien quiere apartarse al proceso de trabajo mecanizado para poder estar de nuevo a tono con él» (Adorno y Horkheimer, 2007, p. 150). Esta mecanización a la que hacíamos referencia hace que el placer o la felicidad buscada acaben, finalmente, convirtiéndose en aburrimiento, al no exigir ningún pensamiento propio.

Esta idea la mantiene también Lukács, para quien «a consecuencia de tal manipulación, al trabajador, a la persona que trabaja, se le desvía de los problemas relacionados con la conversión de sus ratos de ocio en actividad creadora, insinuándosele el consumo como objetivo capaz de colmar su vida, de la misma manera que, en la jornada laboral de 12 horas, impuesta de manera dictatorial, el trabajo había dominado su vida. Surge ahora el problema de tener que organizar una nueva forma de resistencia». (Holz, 1971, p. 74)

Por tanto, el engaño de la industria cultural consiste en ofrecer como paraíso la misma vida cotidiana; emprendemos un camino que «conduce al punto de partida, pero que consigue sin embargo no decepcionarnos del todo, pues juzgamos que merece la pena la diversión del recorrido. La diversión se funde así con la resignación» (Rodríguez, 2012, p. 28). Este entretenimiento, para Adorno, equivale a conformarse. Este conformarse lo tiene en común con la publicidad, que pasamos a analizar a continuación.

\section{El papel de la publicidad en las sociedades}

Como ya vimos, trabajo y entretenimiento se asimilan cada vez más en su estructura. Ello hace necesario separar ambos por líneas invisibles: este espacio será el ocupado por la publicidad.

Las principales obras de Adorno en las que se analiza la relación entre industria cultural y publicidad son La industria cultural. Ilustración como engaño de masas y El esquema sobre la cultura de masas. No obstante, como señala Raúl Rodríguez, en los estudios actuales sobre industrias culturales se obvia a menudo la industria cultural publicitaria. Las posibles explicaciones que ofrece el autor de este olvido -carencia por parte de la publicidad de un soporte propio al que asociarlo de manera estable, la indefinición espacial y su carácter aparentemente informativo- no justifican la ausencia de la publicidad en dichos estudios (Rodríguez, 2012). Los intereses de la publicidad y de los productos de las industrias culturales se hallan íntimamente relacionados.

John Berger resalta la importancia de la publicidad en nuestra vida diaria, ya que en ninguna otra sociedad ha habido tanta concentración de imágenes. El autor afirma que «en las ciudades donde vivimos, todos vemos a diario cientos de imágenes publicitarias. Ningún otro tipo de imagen nos sale al paso con tanta frecuencia» (Berger, 2012, p. 301).

La publicidad y el producto cultural son entidades con la misma sustancia, lo que hace que exista continuidad entre ambas; este hecho es al que hace referencia Adorno cuando afirma que «la cultura de masas es la instalación señalizadora de ella misma» (Adorno y Horkheimer, 2007, p. 301). Mientras el consumo de electrodomésticos se desarrolla en la cocina, en la industria cultural el soporte del producto y su reclamo publicitario son idénticos; es decir, que «los mismos medios de comunicación que soportan estas producciones culturales industriales son los que soportan las piezas publicitarias que apuntan a aquellas» (Rodríguez, 2012, p. 26).

Ya vimos anteriormente cómo la industria cultural no puede generar auténtica satisfacción, lo que hace que necesite de la publicidad para legitimarse, evitando la desidia frente a tal industria. 
En la sociedad competitiva, nos dice Adorno, haciendo referencia al modelo ideal burgués de sociedad, la publicidad se enfocaría a orientar al comprador en la oferta; pero la verdadera función de esta es afianzar el dominio del sistema: la publicidad reforzaría la atadura de los consumidores a las grandes empresas. Lukács se manifiesta en el mismo sentido cuando afirma que «es evidente que esa manipulación del consumo no trata, como afirman los medios oficiales, de informar al consumidor sobre cuál sea el mejor frigorífico o la mejor hoja de afeitar, sino que da lugar a un problema de la dirección de las conciencias» (Holz, 1971, p. 73).

El propósito de la publicidad es modificar la conducta del comprador insatisfecho con el tipo de vida que lleva, de forma que trata de hacerle creer que su existencia puede cambiar a través de los productos que se le ofrecen. Se convence a los individuos para que interioricen en la sociedad una escala de valores en la que no tener nada, equivale a no ser nada. Las consecuencias políticas que conlleva resultan de gran trascendencia. Por un lado, en lugar de intentar reducir la distancia existente entre lo que el comprador es y lo que quiere ser-mediante la actuación práctica y el cambio de las condiciones para evitar que esto ocurra-, se ocupa por una especie de soñar despierto. Y, por otro, «la publicidad convierte el consumo en un sustituto de la democracia. La elección de lo que uno come (o viste, o conduce) ocupa el lugar de la elección política significativa» (Berger, 2012, p. 164). Las carencias políticas son sustituidas por la pretendida libertad que ofrece la publicidad. En cada anuncio, en cada propuesta publicitaria, el mensaje implícito es el mismo: eres libre para tener cualquier cosa de las que te ofrecemos, pero solo si puedes comprarlo.

El propio sistema de la industria cultural acaba convertido en un gran engranaje publicitario, en el que cada pieza es publicidad tanto de sí misma como de las demás: «cada película es el avance publicitario de la siguiente, que promete reunir una vez más a la misma pareja bajo el mismo cielo exótico: quien llega con retraso no sabe si asiste al avance de la próxima película o a la que ha ido a ver» (Adorno y Horkheimer, 2007, p. 177). La reproducción mecánica del producto cultural es ya la propagación de la publicidad.

\section{La exclusión de la industria cultural}

¿Qué provoca, pues, que la gente acepte esta industria cultural? ¿Es por la imagen elitista del ser humano que tiene Adorno, considerándoles estúpidos e incapaces de rebelarse contra la industria?

Nada más alejado de la realidad. Adorno era plenamente consciente de las dificultades que supone para los individuos combatir la industria cultural, y cómo el no rechazo de esta no es porque las masas sean inferiores frente a una supuesta élite ilustrada, sino por el rechazo social que ocasionaría para ellos. El carácter omniabarcante de la industria cultural implica que, salir de ella, puede suponer salir de la sociedad.

En El esquema de la cultura de masas, nos dice Adorno que «no es el "entontecimiento" de las masas, que los enemigos de éstas subrayan y sus amigos filántropos lamentan, lo que hace que la cultura de masas sea tan irresistible» (Adorno y Horkheimer, 2007, p. 312). Lo que la hace indomable es el conocimiento -explícito o implícito- de que quien sale de este sistema se queda solo. Los hombres dicen sí a la cultura de masas «porque saben o presienten que en ella se enseñan las formas de comportamiento que en la vida monopolística necesitan como un pase» (Adorno y Horkheimer, 2007, p. 311). Si deseas llevar una vida normal, si quieres ser aceptado por los demás, debes admitir las normas que se te imponen.

La totalidad de la industria cultural «culmina en la exigencia de que nadie sea distinto de ella misma (...) a quien no va al cine ni aprende a hablar y andar conforme al esquema de la sociedad trazado por el monopolio, éste le cierra las puertas» (Adorno y Horkheimer, 2007, p. 312). La frase típica del entretenimiento burgués: «no puede usted perdérselo», adquiere pleno sentido aquí. Ya no es simplemente una recomendación: ahora continúa apuntándose que «puedes» perdértelo, pero si quieres continuar en la sociedad, si pretendes seguir siendo uno más, «no debes» perdértelo. La obligación es estar al día, repetir mecánicamente las palabras que todos pronuncian, conversar de las películas que todos comentan y, en definitiva, hacer lo que todos hacen: «Hoy, el que no puede hablar de la manera aceptada, es decir, el que no es capaz de reproducir sin esfuerzo las fórmulas, las convenciones y los juicios de la cultura de masas como si fuesen propios, está amenazado en su existencia, es sospechoso de ser un tontito o un intelectual» (Adorno y Horkheimer, 2007, p. 312). En la actualidad, podemos observar cómo este hecho se acentúa con la explosión de plataformas desde las que ver series y 
películas, lo que ha llevado a que buena parte de las conversaciones sean sobre la última serie que no te puedes perder, al menos hasta la semana siguiente que salga la próxima, la cual pasará a ser el nuevo tema de conversación.

Adorno también recoge en La industria cultural. Ilustración como engaño de masas la idea de Tocqueville cuando afirma que el poder no te dice piensa como yo o morirás; ahora, dice "piensa como yo o pasarás a ser un extraño entre nosotros", beneficiándose de la impotencia que la sociedad inculca en aquel que se sale de los cánones establecidos. La sociedad se aprovecha del temor del individuo a sentirse sólo, a como dice Adorno «atraerse la venganza de lo colectivo» (Adorno y Horkheimer, 2007, p. 145).

\section{4. ¿Opciones de resistencia?}

Ya hemos visto alguna de las consecuencias políticas que la industria cultural implica para la sociedad. La industria cultural, como el capitalismo que lo sostiene, destaca por su capacidad de absorción de todas aquellas alternativas que se plantean. Aquí simplemente queremos destacar algunas de las vías que consideramos podrían intentar salirse de esta mecánica.

No creemos que sea casualidad, como señala Alberto Santamaría, que cuanto más trágicas son las consecuencias del neoliberalismo, aumente el interés de ciertas instituciones por las prácticas artísticas participativas. Como señala el autor: «cuando las herramientas críticas se convierten en suave crema reparadora y regeneradora, quizá debamos estar alerta. Ocurre, pues, que muchas veces las obras de arte socialmente orientado lo que llevan a cabo es una reproducción de las políticas de inclusión típicas del neoliberalismo donde la idea de comunidad desaparece surgiendo en su lugar la figura del sujeto consumidor autoadministrado, la empresa-de-sí» (Santamaría, 2019, p. 19). Cierto pretendido arte crítico, en realidad, lo que está haciendo es reforzar la idea de consenso que el neoliberalismo defiende, frente a otro tipo de realidades que introduzca la idea de disenso y confrontación con la realidad.

El ejemplo que utiliza Santamaría es el del apropiacionismo (ver, por ejemplo, p. 80 y siguientes). Si bien en determinado momento, la mezcla entre elementos artísticos y no-artísticos fue utilizada para denunciar las relaciones sociales, así como para defender la necesaria inclusión del arte en la vida y la denuncia del mercantilismo, este apropiacionismo acabará siendo un proceso «sin más trasfondo que el simple interés del artista en mostrar su ingeniosidad formal» (Santamaría, 2019, p. 81). Es decir, ahora es el mercado el que modela el situacionismo y no a la inversa, es un arte que supone «la afirmación superficial de ser una apropiación en el interior maternal del mercado (y de una institución) que la legitima (y aplaude) para ser tal» (Santamaría, 2019, p. 81).

¿Podemos salir de esta dinámica absorbente, característica del capitalismo? Las obras de arte, dice Adorno, son «copias de lo vivo empíricamente en la medida en que proporcionan a éste lo que se le niega fuera, de modo que lo liberan de aquello en que lo convierte su experiencia cósica exterior» (Adorno, 2004, p. 14). Como señala Abadi (Abadi, 2002), esto quiere decir tres cosas. Por un lado, que las obras artísticas toman su contenido de la realidad empírica. Por otro lado, que las obras artísticas niegan la realidad empírica a la que hacíamos referencia. Por último, que la obra de arte es capaz de aportar lo que a la realidad empírica se le ha negado. En este sentido, consideramos que un arte que quiera escapar de las dinámicas capitalistas, deberá tener en cuenta la realidad en la que se encuentra, pero intentando abrir nuevas vías, nuevas alternativas a esta realidad, negándola y aportándole otros matices. Que «El arte es promesa de felicidad pero promesa quebrada» (Adorno, 2004) implica que el arte puede mostrarnos otros caminos al margen de lo meramente existente, pero para lograrlo hace falta cambiar las condiciones materiales de la sociedad.

Eduardo Galeano, en La función del arte/l (Galeano, 2006), cuenta la historia de Diego, quien fue a ver por primera vez el mar junto a su padre. Quedando mudo de impresión, al final consiguió pedirle a su padre: “Ayúdame a mirar”. El arte, tal vez, pueda desempeñar esa función: enseñarnos a ver de otra forma. 


\section{Conclusión}

La intención de este texto era, principalmente, mostrar algunas de las consecuencias más importantes que la industria cultural tiene social y políticamente. Pero también hemos querido, al menos apuntar, que pese a la intrincada síntesis entre capitalismo y arte que supone la industria cultural, consideramos que el arte puede tener la función de explorar y tratar vías alternativas a la realidad fáctica, al orden establecido. No obstante, estas alternativas simplemente son mostradas. El arte, siguiendo a Galeano, nos enseña a mirar, a ver la realidad como es y como podría ser. Pero para plantear cambios significativos, estas panorámicas deben relacionarse con reivindicaciones en la realidad. Si la industria cultural tiene consecuencias políticas, como hemos intentado mostrar, un arte pretendidamente crítico deberá intentar también enlazar con la vida cotidiana y la praxis política.

\section{Referencias}

ABADI, F. (2002) “Diálogo entre Gadamer y Adorno en torno a una definición del arte” en Jornadas de Estética (2002).

Adorno, T., HorkHEIMER, M. (2007). Dialéctica de la ilustración. Madrid : Akal.

Adorno, T. (2006). Minima Moralia. Madrid: Akal.

Adorno, T. (2004). Teoría Estética. Madrid : Akal.

BERGER, J. (2012). Modos de ver. Barcelona: Gustavo Gili.

Galeano, E. (2006). El libro de los abrazos. Madrid: Siglo XXI.

Gramsci, A. (2013). Antología. Madrid: Akal.

Holz, H., Kofler, L., Abendroth, W. (1971). Conversaciones con Lukács. Madrid: Alianza.

JAY, M. (1988). La imaginación dialéctica. Una historia de la Escuela de Frankfurt y el Instituto de Investigación Social (1923-1950). Madrid: Taurus.

RodríGUEZ, R. (2008) “La publicidad como industria cultural” en Pensar en la publicidad (2008, vol.II, n 1, 2008, pp. 19-36).

Santamaría, A. (2019). Alta cultura descafeinada: situacionismo low cost y otras escenas del arte en el cambio de siglo. Madrid: Siglo XXI. 